\title{
Theory and experiments on evaporating sessile drops of binary liquid mixtures
}

\author{
WEN-JEI YANG and $\mathrm{K}$. H. GUO \\ Department of Mechanical Engineering and Applied Mechanics, The University of Michigan, \\ Ann Arbor, MI 48109, U.S.A. \\ and

\section{T. UEMURA} \\ Department of Mechanical Engineering, Faculty of Engineering Science, Osaka University, \\ Toyonaka, Japan
}

(Received 4 February 1988 and in final form 29 September 1988)

\begin{abstract}
Theoretical and experimental studies are performed to determine the size, history and lifetime of evaporating sessile drops of binary liquid mixtures. The minimum and maximum drop lifetimes (equivalent to the maximum and minimum vaporization rates, respectively) occur at the azeotropic compositions of the positive and negative azeotropes, respectively. The mechanisms leading to the extremum drop lifetime are due to the changes in composition of the more volatile component during the vaporization process. This composition change tends to suppress vaporization. A new dimensionless parameter is found to determine the intensity of vaporization of a binary liquid drop. Theoretical predictions of the drop size, history and lifetime agree satisfactorily with experimental results.
\end{abstract}

\section{INTRODUCTION}

VAPORIZATION is the process of mass transfer from the liquid phase into the vapor phase. It may exhibit itself in two basic types: boiling and convective type vaporizations. When the surrounding temperature $T_{\infty}$ is equal to or higher than the boiling temperature $T_{\mathrm{b}}$, the vaporization rate, to a great extent, is controlled by the heat flux from the surroundings to the drop. This is the boiling type vaporization. On the other hand, if $T_{\infty}$ is below $T_{b}$, the vaporization process is governed by mass diffusion of the vapor into the ambient. The concentration of the vapor at the drop surface is determined by the vapor-liquid phase equilibrium of the vapor-air mixture.

In the case of the binary liquid mixtures, the equilibrium vapor pressure $P$ depends on both the temperature $T$ and composition, $\bar{x}_{i}$ or $\bar{y}_{i} \cdot \bar{x}_{i}$ and $\bar{y}_{i}$ denote the mole fractions of component $i$ in the liquid and vapor phases, respectively. The binary vapor-liquid equilibrium (VLE) may be expressed two-dimensionally in two different forms $T$ vs $\left(\bar{x}_{i}, \bar{y}_{i}\right)$ at constant $P$ and $P$ vs $\left(\bar{x}_{i}, \bar{y}_{i}\right)$ at constant $T$. In both forms, the phase equilibrium diagram is characterized by two curves, called bubble- (or boiling-) and dew-point curves representing the states of saturated liquid and vapor, respectively. For non-azeotropic binary mixtures such as carbon disulfide-benzene mixtures, the bubble- and dew-point curves form a 'lens' shape in both the $T-x$ and $P-x$ diagrams, not shown. The significant feature of Figs. 1(a) and (b) is the occurrence of a state of intermediate composition at which the equilibrium liquid and vapor compositions are identical. Such a state is called an azeotrope which is characterized by the extremum on both the bubbleand dew-points curves under the isothermal conditions. The mixture with the maximum is called the positive azcotrope, whilc that with the minimum is referred to as the negative azeotrope [1].

It is known that the addition of a foreign component into a pure liquid results in natural convection with the aid of solutal effects. Two important phenomena were disclosed in the boiling type vaporization in binary liquid mixtures. One was the nucleate pool boiling in a large volume of non-azeotropic mixtures, which disclosed the coincidence of the minimum bubble growth rate and the maximum heat flux at the same composition. This peculiar phenomenon, called 'boiling paradox', has attracted considerable interest in the past decade [2]. The other phenomenon was the disclosure of the minimum lifetime (or equivalently the maximum evaporation rate) of an azeotropic binaryliquid drop evaporating on a plate in the nucleateboiling type evaporation regime with the plate temperature between the boiling point and the DNB (deviation from nucleate boiling) point [3].

Recently, real-time holographic interferometry was employed to determine the concentration effect on the binary drop lifetime in the whole concentration range of $0-100 \%$ volume ethyl ether in chloroform [4]. The minimum drop lifetime was discovered at an intermediate composition. An examination revealed that the composition corresponding to the minimum lifetime coincided with the azeotropic composition of the binary mixture which is a positive azeotrope. The 


\section{NOMENCLATURE}

$A_{\mathrm{s}} \quad$ drop surface area $\left[\mathrm{m}^{2}\right]$

$\begin{array}{ll}B & \bar{x}_{\mathrm{a}} /\left(1-\bar{x}_{\mathrm{a}}\right)\end{array}$

$C$ concentration $\left[\mathrm{kg} \mathrm{m}^{-3}\right] ; C_{\mathrm{b}}$, of drop; $C_{\infty 0}$, of surroundings

$C_{p} \quad$ specific heat $\left[\mathrm{kJ} \mathrm{kg}^{-1} \mathrm{~K}^{-1}\right]$

$F$ shape factor of drop, $A_{\mathrm{s}} / V\left[\mathrm{~m}^{-1}\right]$

$F^{*} \quad F V_{0}^{1 / 3}$

$f_{i} \quad$ fugacity of $i$ th component; $f_{i L}$, of liquid phase $; f_{i 0 l}$, pure-liquid reference value (at zero reference pressure)

$\bar{f}_{1}$ molar fugacity of $i$ th component $; \bar{f}_{i \mathrm{~L}}$, of liquid phase; $\bar{f}_{i \mathrm{~V}}$, of vapor phase

$G$ dimensionless parameter defined by equation (15)

$h$ drop surface-ambient heat transfer coefficient $\left[\mathrm{W} \mathrm{m}^{-2 \circ} \mathrm{C}^{-1}\right]$

$h_{\mathbf{D}}$ drop surface-ambient mass transfer coefficient $\left[\mathrm{m} \mathrm{s}^{-1}\right]$

$h_{\mathrm{fg}}$ latent heat of vaporization $\left[\mathrm{kJ} \mathrm{kg}^{-1}\right]$

$k_{i} \quad \tilde{y}_{i} / \tilde{x}_{i}$

$l$ drop height of spherical segment [m]

$M_{\mathrm{b}}$ molecular weight of binary mixture $\left[\mathrm{kg} \mathrm{kmol}^{-1}\right] ; M_{\mathrm{ba}}$, at azeotrope; $M_{\mathrm{bL}}$, of liquid phase; $M_{\mathrm{hV}}$, of vapor phase

$m$ mass $[\mathrm{kg}] ; m_{0}$, at initial state

$m^{*} \quad m / m_{0}$

$P \quad$ pressure $[\mathrm{Pa}] ; P_{\mathrm{b}}$, equilibrium vapor pressure of binary system; $P_{\mathrm{ba}}, P_{\mathrm{b}}$ at azeotrope

$P^{*} \quad P_{\mathrm{b}} / P_{\text {ba }}$

$q_{\mathrm{s}} \quad$ rate of heat transfer across drop base [W]

$\bar{R} \quad$ radius of curvature of spherical-segment drop $[\mathrm{m}]$

$R \quad$ universal gas constant $\left[\mathrm{kJ} \mathrm{kmol}^{-1} \mathrm{~K}^{-1}\right]$

$r$ base radius of spherical-segment drop [m]

$S_{\mathrm{a}} \quad$ parameter defined by equations (26) and (27)

$T$ lemperature $\left[{ }^{\circ} \mathrm{C}\right], T_{\mathrm{b}}$, builing, $T_{x:}$ of ambient

$t$ time [s]

$t^{*} \quad t h_{\mathrm{D}} / v_{0}^{1 / 3}$

$V$ drop volume $\left[\mathrm{m}^{3}\right] ; V_{0}$, initial state

$v \quad$ specific volume $\left[\mathrm{m}^{3} \mathrm{~kg}^{-1}\right] ; v_{\mathrm{b}}$, binary system; $v_{\mathrm{b}, 0}$, at initial state

$\bar{v} \quad$ molar volume $\left[\mathrm{m}^{3} \mathrm{~mol}^{-1}\right] ; \bar{v}_{\mathrm{b}}$, binary system ; $\bar{v}_{\mathrm{ba}}$, at azeotrope; $\bar{v}_{\mathrm{b} 0}$, at initial state

$\bar{v}^{*} \quad \bar{v}_{\mathrm{b}} / \bar{v}_{\mathrm{b} \mathrm{o}}$

$v^{*} \quad v_{\mathrm{b}} / v_{\mathrm{b} 0}$

$x_{i} \quad$ mass fraction of $i$ th component in liquid phase $; x_{\mathrm{a}}$, at azeotrope $\bar{x}_{3} \quad$ mole fraction of $i$ th component in liquid phase $; \bar{x}_{a}$, at azeotrope $; \bar{x}_{1}$, of more volatile component

$\bar{x}_{10}$ initial volumetric fraction of liquid mixture

$y$ mass fraction of $i$ th component in vapor phase

$\bar{y}_{i} \quad$ mole fraction of $i$ th component in vapor phase

$Z_{\mathrm{a}} \quad \bar{V}_{\mathrm{ba}} P_{\mathrm{ba}} /\left(\tilde{R} T_{\infty \mathrm{s}}\right)$.

\section{Greek symbols}

$\alpha \quad$ shape parameter as defined in equation (5) $; \alpha_{i}$, of $i$ th component in liquid phase

$\beta \quad$ contact angle between drop and substrate [rad]

$\gamma_{t}^{0} \quad$ activity coefficient of $i$ th component in liquid phase at reference pressure (taken to be zero pressure)

$\varepsilon_{\mathrm{b}} \quad$ non-ideal mixing factor as defined by equation (25)

$\xi \quad$ correction factor as defined by equations (22) and (25)

$\phi_{\mathrm{h}} \quad$ correction parameter for non-ideal mixing of binary vapor with surrounding gases, similar to $\phi_{i}$

$\phi_{i} \quad$ fugacity coefficient for $i$ th component in vapor phase

$\psi \quad$ shape parameter as defined by equation (5)

$\psi^{*} \quad$ dimensionless shape parameter as defined by equation (16).

Superscripts

L liquid phase

V vapor phase

0 reference state

1 component 1 (more volatilc)

- molar basis

* dimensionless quantity.

\section{Subscripts}

a azeotropic composition

b binary mixture

$i \quad i$ th component

L liquid phase

S substrate surface

$\mathrm{V}$ vapor phase

$0 \quad$ initial state

$\infty$ surroundings. discovery has motivated the present study which, both theoretically and experimentally, correlates the minimum and maximum drop lifetimes with the azeotropic composition of the positive and negative azeotropes.
Theoretical results are compared with experimental data. Sessile drops are under the liquid-film type evaporation regime [5] in which natural convection occurs within the liquid phase. Results cannot be applied 


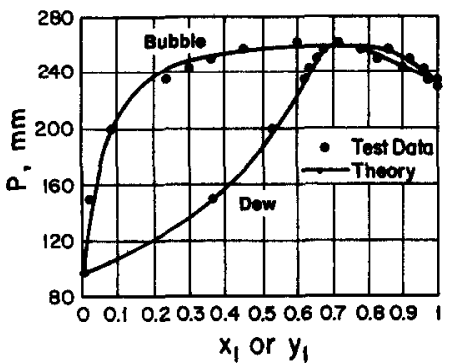

(a)

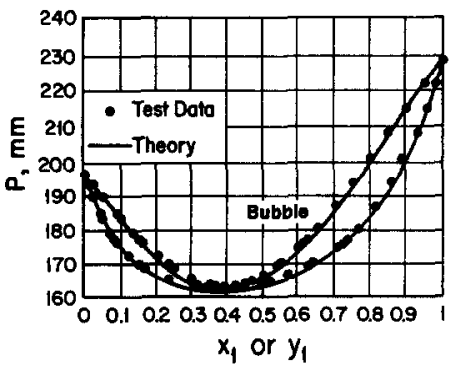

(b)

FIG. 1. Binary vapor-liquid phase equilibrium $(P-\bar{x})$ diagrams at $25^{\circ} \mathrm{C}$ for : (a) positive azeotrope, acetonecyclohexane mixtures; (h) negative azeotrope, acetone-chloroform mixtures. data from ref. [1].

to other evaporation regimes and, in particular, are irrelevant to drop combustion. It is important to note that the famous $d^{2}$ law for drops in spheroidal combustion is not applicable to the present study. The study is based on the perfect mixing model and can be applied to spray cooling in materials processing and energy shutdown of nuclear reactors.

\section{THEORY}

Transport phenomena related to the vaporization of a binary liquid drop on a substrate are very complex, involving buoyancy- and thermocapillaryinduced double diffusion, drop shape and couplings at the phase interfaces. It is difficult to analytically or numerically obtain the general solutions. Therefore, the following assumptions are imposed in order to simplify the formulation.

(1) Because of a minute size with vigorous internal circulation [5], the drop is a lumped system, uniform in both temperature and concentration at any instant. The perfect mixing model is appropriate for the following reasons.

(a) The drop forms a thin liquid layer of lens shape with a maximum height of $0.2-0.3 \mathrm{~mm}$.

(b) Rigorous flow circulation takes place within the liquid phase as revealed by flow visualization [5].

(c) The phenomenon is entirely different from that which occurs in drops under spheroidal combustion during which the drop is spherical and stagnant. It should be noted that for the case with liquid-side heat transport by conduction and gas-side transport by natural convection, the Biot number is estimated to be less than 0.1 for the liquids used in the present study. The flow may not be laminar due to the effects of Marangoni instability [6]. The circulating flow can substantially promote the uniformity in temperature and concentration distribution within the drop.

(2) All physical properties remain unchanged during the evaporation process.

(3) The gas-side transport phenomena are simplified through the use of heat and mass transfer coefficients ( $h$ and $h_{\mathrm{D}}$, respectively) betwoen the drop surface and the ambient. The assumption is valid since the drop is placed on a plate so that the change of $h_{\mathrm{D}}$ and $h$ with drop size is small.

The mass and heat balance for the drop read, respectively

$$
\begin{gathered}
\frac{\mathrm{d} m}{\mathrm{~d} t}=-h_{\mathrm{d}} A_{\mathrm{s}}\left(C_{\mathrm{b}}-C_{\infty}\right) \\
m C_{p} \frac{\mathrm{d} T}{\mathrm{~d} t}=-h A_{\mathrm{s}}\left(T-T_{\infty}\right)+q_{\mathrm{s}}-h_{\mathrm{D}} A_{\mathrm{s}}\left(C_{\mathrm{b}}-C_{\infty}\right) h_{\mathrm{fg}}
\end{gathered}
$$

The symbols are defined in the Nomenclature. The change of compositions in the binary liquid drop is derived from the discontinuity of concentrations at the drop surface as

$$
\frac{\mathrm{d} x_{i}}{\mathrm{~d} t}=-\frac{x_{i}-y_{i}}{m} h_{\mathrm{D}} A_{\mathrm{s}}\left(C_{\mathrm{b}}-C_{\infty}\right) .
$$

Here, $x_{i}$ and $y_{i}$ denote the mass fractions in the liquid and vapor phases, respectively, under phase equilibrium.

The drop surface area $A_{\mathrm{s}}$ is related to the drop volume $V$ by the shape factor $F$ as

$$
A_{\mathrm{s}}=F V .
$$

For the drops of spherical-segment shape, $F$ can be further generalized as the product of two quantities: one depends on the drop volume as $2(\pi / v)^{\alpha}$, while the other quantity $\psi$ is insensible to the volume change. It reads

$$
F=2(\pi / v)^{x} \psi
$$

Here, $\alpha$ and $\psi$ are named shape parameters which vary with only the shape that the drop forms on the substrate. The sessile drops undergoing stable interfacial type evaporation take a lens shape which can be idealized as a spherical segment, as depicted in Fig. 2. In general, $\alpha$ and $\psi$ can be determined by two of the four variables $R, r, l$ and $\beta$. Since the drop shape depends on the temperature, compositions and drop volume which vary with time, the shape parameters are time dependent. The role of drop shape on the evaporation process is presented later in Section 3.

During the vaporization process with the shape of a spherical segment, three special cases are of interest. 


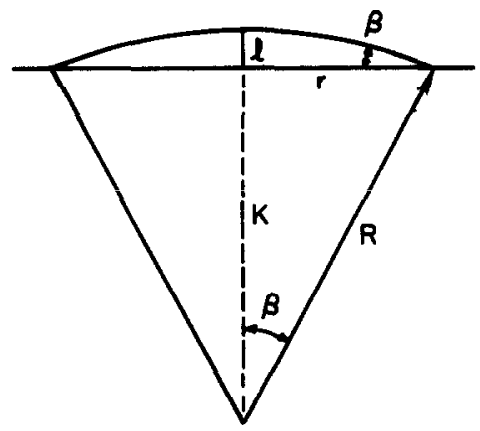

FIG. 2. Geometry of a spherical-segment drop on a flat plate.

(1) Prescribed base radius $r$ : with a given $r$, the surface area-volume ratio of the spherical segment is obtained and compared with equation (5). It yields

$$
\alpha=1 ; \quad \psi=\frac{1}{2} r^{2}\left[1+\left(\frac{l}{r}\right)^{2}\right]
$$

For $(l / r)^{2} \ll 1, \psi$ is approximately $r^{2} / 2$ which stays nearly constant. Liquids such as acetone, ethanol, methanol, and ethyl acetate belong in this category [5].

(2) Prescribed radius of curvature $R$ : similar to the procedure described in equation (1), one obtains

$$
\alpha=\frac{1}{2} ; \quad \psi=R^{1 / 2}\left[1-\left(\frac{l}{3 R}\right)^{2}\right]^{-1 / 2}
$$

For $(l / 3 R) \ll 1, \psi$ can be approximated as $R^{1 / 2}$ and remains almost constant. Cyclohexane, methylene chloride, ethyl ether and benzene are of this type [5].

(3) Prescribed contact angle $\beta$ : in this case, it yields

$$
\alpha=\frac{1}{3} ; \quad \psi=\left[\frac{1-\cos \beta}{1-\frac{1}{3}(1-\cos \beta)}\right]^{1 / 3}
$$

\section{A liquid of this type is chloroform [5].}

In general, $\alpha$ lakes a value between $1 / 3$ and 1 , while the value of $\psi$ does not change significantly with a reduction in drop size. If the drop temperature variation is small, $\alpha$ and $\psi$ for pure liquid drops may be considered constant during vaporization. In the case of hinary liquid drops, however, a mixing rule can be imposed to describe the dependence of the shape factors of individual constituents on their compositions. The present study uses

$$
F=\prod_{i=1}^{2} f_{i}^{\bar{x}_{i}}=2\left(\frac{\pi}{V}\right)^{\sum_{i=1}^{2} \bar{x}_{i} \alpha_{i}} \prod_{i=1}^{2} \psi_{i}^{\bar{x}}
$$

Here, $\alpha_{i}$ and $\psi_{i}$ denote the shape parameters for pure liquid drops at the same temperature and initial volumes, while $\bar{x}_{i}$ represents the mole fraction of component $i$ in the binary liquid phase. The mixing rule employed in this study is based on the boundary condition that the shape factor of a pure liquid component should be recovered when the mole fraction of that component becomes unity.
The concentration difference $\left(C_{\mathrm{b}}-C_{\alpha_{c}}\right)$ is the driving force for drop vaporization. For simplicity $C_{x}$ may be assumed zero, while $C_{\mathrm{b}}$ depends on the VLE conditions of the binary system. The conventional thermodynamic approach [7] yields

$$
C_{\mathrm{b}}=\frac{M_{\mathrm{bV}} P_{\mathrm{b}}}{\bar{R} T \phi_{\mathrm{b}}} \exp \left[\int_{P_{\mathrm{b}}}^{P} \bar{t}_{\mathrm{bL}} \mathrm{d} p\right] .
$$

The exponent is called the Poynting correction. It is nearly unity when the liquid molar volume $\vec{v}_{\mathrm{bL}}$ is small and the total system pressure is moderate. Equation (10) then becomes

$$
C_{\mathrm{b}}=\frac{M_{\mathrm{bV}} P_{\mathrm{b}}}{\bar{R} T \phi_{\mathrm{b}}} .
$$

Here $P_{\mathrm{b}}$ is the equilibrium vapor pressure of the binary system at temperature $T$ and liquid phase composition $\bar{x}_{i}$. The mean molecular weight of the binary vapor at the phase composition $\bar{y}_{t}$, is denoted by $M_{\mathrm{bv}}$, while $\phi_{\mathrm{b}}$ is the correction parameter (similar to the fugacity coefficient) for non-ideal mixing of the binary vapor with the surrounding gases.

To simplify the analysis, it is assumed that heat transfer from the surrounding atmosphere is negligible and that the heat of vaporization comes from the substrate through the drop base. Energy equation (2) can thus be excluded from the consideration. The main objective of the study is to determine the effects of binary composition on the drop lifetime. Now, equations (4) and (9) are substituted into equations (1) and (3), followed by non-dimensionalizing the variable using

$$
\begin{gathered}
m^{*}=\frac{m}{m_{0}} ; \quad F^{*}=F V_{0}^{1 / 3} ; \quad v_{\mathrm{b}}^{*}=\frac{\bar{v}_{\mathrm{b}}}{\bar{v}_{\mathrm{b} 0}} \\
t^{*}=\frac{t h_{\mathrm{D}}}{V_{0}^{1 / 3}} ; \quad P^{*}=\frac{P_{\mathrm{b}}}{P_{\mathrm{ba}}} .
\end{gathered}
$$

After some manipulation, it yields

$$
\begin{gathered}
\frac{\mathrm{d} m^{*}}{\mathrm{~d} t^{*}}=-m^{*} G \\
\frac{\mathrm{d} x_{1}}{\mathrm{~d} t^{*}}=-\left(x_{1}-y_{1}\right) G .
\end{gathered}
$$

Here

$$
\begin{aligned}
G=Z_{\mathrm{a}} \frac{\bar{v}_{\mathrm{b}}^{*} P_{\mathrm{b}}^{*}}{\phi_{\mathrm{b}}}\left(\frac{\bar{v}_{\mathrm{ba}}}{\bar{v}_{\mathrm{b} 0}}\right) & \left(\frac{M_{\mathrm{bV}}}{M_{\mathrm{bL}}}\right) \\
& \times\left[2\left(\frac{\pi}{m^{*} v_{\mathrm{b}}^{*}}\right)^{\sum_{i=1}^{2} \bar{x}_{i} \alpha_{t}} \prod_{i=1}^{2} \psi_{i}^{* \bar{x}_{\mathrm{t}}}\right] .
\end{aligned}
$$

The dimensionless shape parameter, $\psi^{*}$, for a pure liquid $i$, can be expressed as :

case 1

$\psi^{*}=\frac{1}{2}\left[\frac{\sin \beta_{i}}{\pi^{1 / 3}\left(1-\cos \beta_{i}\right)^{2 / 3}\left[1-\frac{1}{3}\left(1-\cos \beta_{i}\right)\right]^{1 / 3}}\right]^{2}$ 
case 2

$$
\psi^{*}=\left[\pi^{1 / 3}\left(1-\cos \beta_{i}\right)^{2 / 3}\left[1-\frac{1}{3}\left(1-\cos \beta_{i}\right)\right]^{1 / 3}\right]^{-1 / 2} ;
$$

case 3

$$
\psi^{*}=\left[\left(1-\cos \beta_{i}\right)\left[1-\frac{1}{3}\left(1-\cos \beta_{i}\right)\right]^{2}\right]^{-1 / 3} ;
$$

where $\beta_{i}$ is the initial contact angle of a pure liquid $i$ on the substrate.

The variables $T, P_{\mathrm{b}}, x_{i}$, and $y_{i}(i=1,2)$ in cquations (13)-(15) are the intensive properties in the VLE. According to the Gibbs phase rule, only two of the six variables are independent. If $T$ and $P$ are chosen as independent variables, the other four must be determined from the conditions of phase equilibrium

$$
\bar{f}_{i}^{\mathrm{V}}=\bar{f}_{i}^{\mathrm{L}}
$$

for $i=1,2$ and the constraints

$$
\sum_{i=1}^{2} \bar{x}_{i}=\sum_{i=1}^{2} \bar{y}_{i}=1
$$

The partial molar fugacities, $\bar{f}_{i}^{\mathrm{V}}$ and $\bar{f}_{i}^{\mathrm{L}}$ for the vapor and liquid phases; respectively, can be written as [7]

$$
\begin{gathered}
\bar{f}_{i}^{\mathrm{v}}=\phi_{i} \bar{y}_{i} P_{0} \\
f_{i}^{\mathrm{L}}=\gamma_{i}^{0} \bar{x}_{i} f_{i}^{0 \mathrm{~L}} \exp \left(\frac{P_{\mathrm{b}} \bar{v}_{i}}{\bar{R} T}\right)
\end{gathered}
$$

for $i=1,2$. Introducing the ratio of mole fractions $k_{i}=y_{i} / x_{i}$, one can write

$$
k_{i}=\frac{\bar{y}_{i}}{\bar{x}_{i}}=\frac{\gamma_{i}^{0}}{\phi_{i} P_{\mathrm{b}}} f_{i}^{01} \exp \left(\frac{P_{\mathrm{b}} \bar{v}_{i}}{\bar{R} T}\right)
$$

for $i=1,2$.

The method given in ref. [8] can be used to determine $\phi_{i}, \gamma_{i}^{0}, f_{i}^{0 \mathrm{~L}}$ and $v_{i}$. Alternately $\bar{v}_{\mathrm{b}}$ can be evaluated using the same equation for a pure liquid in terms of Kay's rule. However, $\phi_{\mathrm{b}}$ for a multicomponent system is hard to predict under equilibrium conditions. It is approximately unity for non-azeotropic mixtures, because a dilute mixture in the gaseous phase behaves like an ideal gas under moderate pressure. For azeotropic binary vapors, $\phi_{\mathrm{b}}$ deviates from unity, reaching the extremum at the azeotropic composition $\bar{x}_{\mathbf{a}}$. Therefore, one can write

$$
\phi_{\mathrm{b}}=1+\xi
$$

where $\xi$ is a weak function of compositions in the vapor phase. $\xi$ must satisfy the following constraints :

$$
\begin{gathered}
\xi \rightarrow \text { extremum, as } \bar{y} \rightarrow \bar{x}_{\mathrm{a}} \\
\xi \rightarrow 0, \quad \text { as } \bar{y} \rightarrow 0 \text { or } 1 .
\end{gathered}
$$

$\xi$ which satisfies constraints (23) and (24) takes the form

$$
\xi=\varepsilon_{\mathrm{b}} S_{\mathrm{a}}(\bar{y})
$$

Here

$$
\begin{gathered}
S_{\mathrm{a}}=\left(\frac{1-\bar{y}}{1-\bar{x}_{\mathrm{a}}}\right)\left(\frac{\bar{y}}{\bar{x}_{\mathrm{a}}}\right)^{B} \text { for } \bar{x}_{\mathrm{a}} \geqslant 0.5 \\
S_{\mathrm{a}}=\left(\frac{1-\bar{y}}{1-\bar{x}_{\mathrm{a}}}\right)^{1 / B}\left(\frac{\bar{y}}{\bar{x}_{\mathrm{a}}}\right) \text { for } \bar{x}_{\mathrm{a}} \leqslant 0.5 \\
B=\frac{\bar{x}_{\mathrm{a}}}{1-\bar{x}_{\mathrm{a}}} .
\end{gathered}
$$

The non-ideal mixing factor $\varepsilon_{\mathrm{b}}$ varies with composition, temperature and pressure. It is determined by curve-fitting the test data.

\section{RESULTS AND DISCUSSION}

The mass balance and composition equations, equations (13) and (14), respectively, are subject to constraints (18) and binary vapor-liquid phase equilibrium conditions (21). The governing equations are numerically integrated by the Runge-Kutta-Gill method. Results are presented in Figs. 3(a) and 4(a) for acetone-cyclohexane mixtures at $14^{\circ} \mathrm{C}$.

It is seen in Fig. 3(a) that the time history of evap-
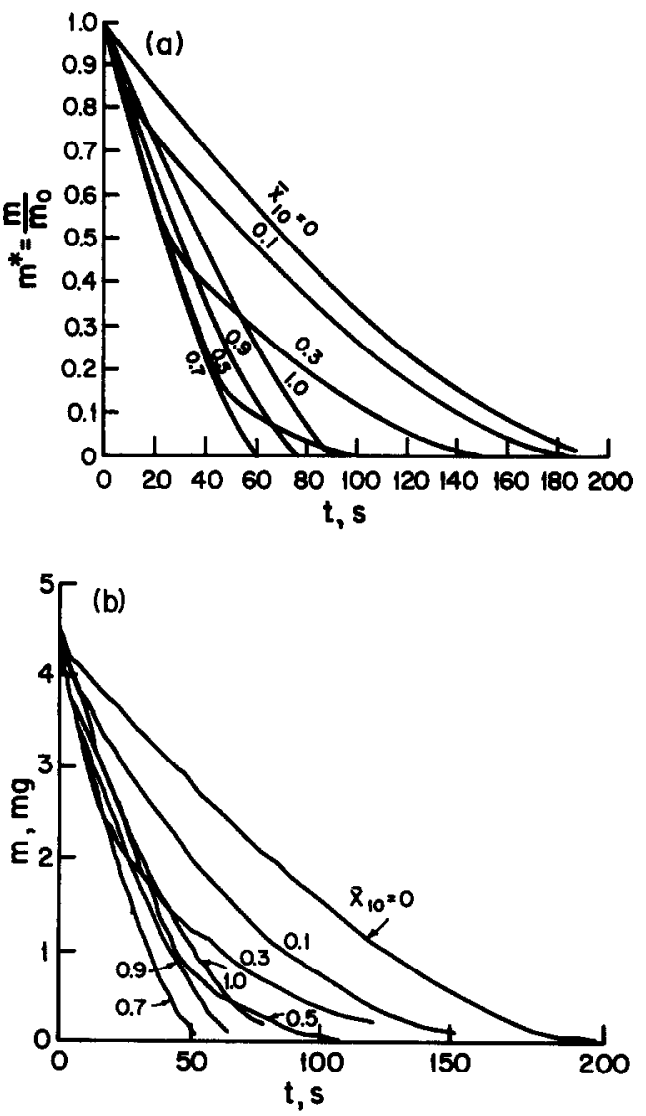

Fig. 3. Time history of drop mass of acetone-cyclohexane mixtures with various initial compositions evaporating in air at $14^{\circ} \mathrm{C}$ : (a) theory; (b) experiments $x_{10}$ in volume fraction. 


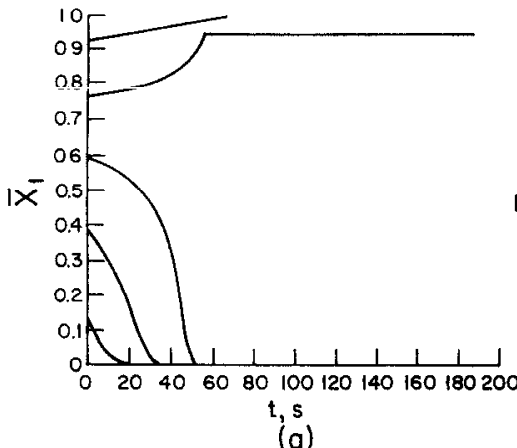

(a)

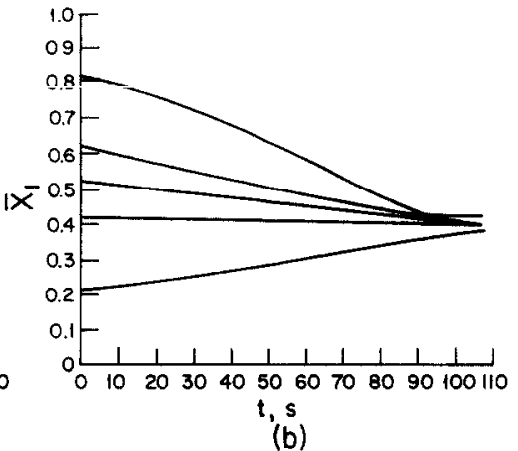

(b)

FIG. 4. Theoretical time history of liquid compositions in binary liquid drops evaporating in air: (a) positive azeotrope, acetone-cyclohexane mixtures at $T_{\infty}=14^{\circ} \mathrm{C} ;(\mathrm{b})$ negative azeotrope, acetone-chloroform mixtures at $T_{\iota}=18^{\circ} \mathrm{C}$

oration rates varies with the initial composition. The fastest evaporation rate occurs at the initial acetone composition of 0.7 by volume, which is about the azeotropic composition. Figure 4 depicts that the drop composition varies drastically with time. Figure 4(a) is for the acetone-cyclohexane mixtures, a positive azeotrope, at $14^{\circ} \mathrm{C}$. If the initial acetone composition $\bar{x}_{10}$ is less than the azeotrope $\bar{x}_{\mathrm{a}}$, of 0.72 then the acetone composition $\bar{x}_{1}$ diminishes toward zero with time as vaporization progresses. On the other hand, if $\bar{x}_{10}>\bar{x}_{\mathrm{a}}$, then $\bar{x}_{1}$ increases toward unity with time. The phenomena can be explained using the $P-x$ diagram in Fig. 1(a). For $\bar{x}_{10}<\bar{x}_{\mathrm{a}}$, the acetone composition in the vapor phase $\bar{y}_{1}$ is greater than that in the liquid phase $\bar{x}_{1}$ at a given pressure. As vaporization proceeds, more liquid acetone evaporates, resulting in a continuous reduction in $\bar{x}_{1}$. Conversely, for $\bar{x}_{10}$ exceeding $\bar{x}_{\mathrm{a}}, \bar{y}_{1}$ is lower than $\bar{x}_{1}$ and both increase as vaporization progresses. Figure $4(\mathrm{~b})$ is the $\bar{x}_{1}-t$ diagram for the acetone-chloroform mixture, a negative azeotrope, at $18^{\circ} \mathrm{C}$. It is observed that $\bar{x}_{1}$ congregates to the azeotropic composition $\bar{x}_{a}$, irrespective of $\bar{x}_{10}$ being greater than or less than $\bar{x}_{\mathrm{a}}$. This phenomenon is seen in Fig. 1(b) : as vaporization proceeds, $\bar{x}_{1}$ moves along the dew line toward $\bar{x}_{\mathrm{a}}$ with any values of $\bar{x}_{10}$. For both the positive and negative azeotropes, a change in $\bar{x}_{1}$ causes a lowering of the equilibrium vapor pressure, resulting in a reduction of the vaporization rate. It is thus concluded that the composition change in a binary liquid drop during the vaporization process causes the suppression of vaporization.

Figures 5(a) and (b) plot the drop lifetime vs composition for acetone-cyclohexane and acetonechloroform mixtures, respectively. In each figure, the solid and broken lines represent different values of $Z_{\text {a }}$ which depends on the ambient conditions $\left(T_{\infty}, P_{\infty}\right)$ and the azeotropic properties (such as $P_{\mathrm{ba}}$ ). It is observed that the larger $Z_{\mathrm{a}}$ is, the shorter is the drop lifetime, implying a stronger vaporization. Therefore, $Z_{\mathrm{a}}$ reflects the strength of vaporization. The most noteworthy is the coincidence of the extreme (maximum or minimum) lifetime with the extreme pressure in Fig. 1, at the same azeotrope. A minimum amount of energy is required for vaporization at the azeotropic composition, in the case of a positive azeotrope which is characterized by the minimum boiling point (on the $T$ vs $x_{1}$ or $y_{1}$ plot, not shown). Therefore, the drop lifetime is a minimum at the azeotrope but the combined thermal and solutal Marangoni effects on internal circulation within the drop reach a maximum. At the azeotrope where the equilibrium liquid and vapor compositions are identical, the vaporization speed should be a maximum because the process requires no mass transfer which is usually an order of magnitude slower than heat transfer. The situation is opposite in the case of a negative azeotrope. The heat for evaporation is a maximum at the azeotrope which is characterized by the maximum boiling point. Accordingly, the drop would take a maximum time to complete its evaporation process, while the combined thermal and solutal Marangonı effects on natural circulation inside the drop achieve a minimum.

Numerical computations reveal that drop shape has a strong influence on the vaporization process. For a sessile drop, its shape is characterized by the two
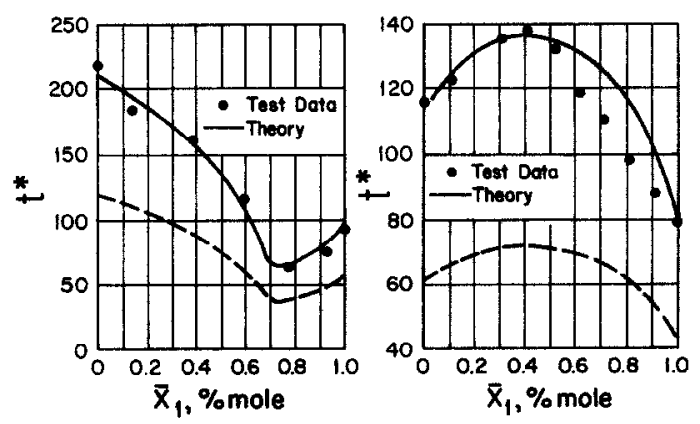

Fig. 5. Lifetime of binary liquid drops evaporating in air: (a) positive azeotrope, acetone-cyclohexane mixtures with $Z_{\mathrm{a}}=0.713 \times 10^{-3}$ (solid line) and $1.24 \times 10^{-3}$ (broken line); (b) negative azeotrope, acetone-chloroform mixtures with $Z_{\mathrm{a}}=0.433 \times 10^{-3}$ (solid line) and $0.821 \times 10^{-3}$ (broken line) 


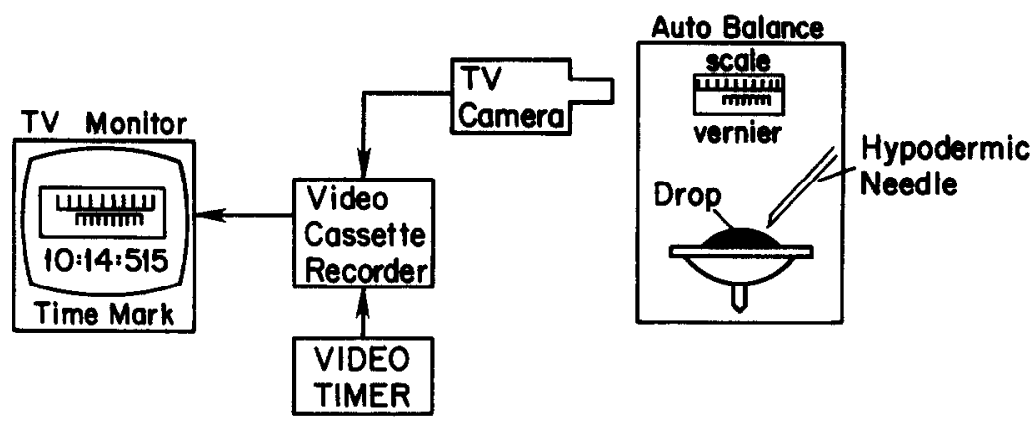

FIG. 6. A schematic of the experimental apparatus for drop evaporation.

parameters $\alpha$ and $\psi$. In the case of a binary liquid mixture, the parameters are determined by those of the constituent pure liquids under the same conditions by means of the mixing rule. The shape type is characterized by $\alpha$, while $\psi$ depends on both the initial size and the contact angle with the substrate. Both the drop shape and contact angle can be determined by a simple optical technique, called the reflection-interference method [9]. The values of $\alpha$ and $\psi$ for three different types of drop vaporization, on a clean glass plate into the atmosphere, are found to be: acetone $(\alpha=0.85, \psi=1.7)$, cyclohexane $(0.65,1.8)$ and chloroform $(0.45,3.5)$, by observation. The binary vapor of an azeotropic mixture, such as acetonechloroform or acctone-cyclohexanc, mingled in a non-condensable gas (such as air in the atmosphere) behaves as a non-ideal mixture. The non-ideal mixing factors for the two typical binary mixtures (one positive the other negative azeotrope) are obtained to be $\varepsilon_{\mathrm{b}}=-0.25$, for acetone-cyclohexane (with $x_{\mathrm{a}}=0.72$ ) and $\varepsilon_{\mathrm{b}}=0.06$, for acetone-chloroform (with $x_{\mathrm{a}}=0.39$ ), by fitting the experimental data.

\section{EXPERIMENTAL APPARATUS AND PROCEDURE}

The experimental apparatus is schematically illustrated in Fig. 6. It consisted of a precision auto balance, a TV camera, a video cassette recorder, a video timer and a TV monitor. A glass plate was placed on the tray of the auto balance. The balance scale was automatically read by the TV camera and recorded in the video cassette, from the instant a liquid drop was placed on the plate until the completion of drop evaporation. An enlarged scale was installed on the auto balance for easier readings. The experimental procedure is as follows.

(1) The auto balance was balanced after the glass plate was placed on the receiving tray.

(2) A TV camera recorded the scale readings. Simultaneously, the video timer set a $1 / 100 \mathrm{~s}$ time scaling on the TV screen.

(3) A minute drop was carefully placed on the glass plate by means of a hypodermic needle and the video recorder began to monitor the change of the scale.
(4) Video recordings were played back on the TV monitor and the time mark for every $0.1 \mathrm{mg}$ change in drop mass was read.

The step response of the auto balance was investigated to determine the recovery characteristics of the balance scale from a shock resulting from the placement of a liquid drop. In order to determine the mechanical instability at small times following a step disturbance, a water drop with very slow evaporation was used to monitor the variation of scale readings. The scale read a slightly higher value (an overshoot of $0.2 \mathrm{mg}$ for a $9.4 \mathrm{mg}$ water drop) over approximately a few seconds and then became stabilized (at a reading of $9.4 \mathrm{mg}$ ), see Fig. 7. Hence, the step-response time (for an overshoot to completely decay) is about 4-8 s for drops of 5-10 $\mathrm{mg}$. The existence of the stepresnonse time was demonstrated in all tests in the form of a rapid fall of drop mass, as seen in Fig. 3(b).

\section{EXPERIMENTAL RESULTS AND COMPARISON WITH THEORY}

Azeotropic mixtures of acetone (more volatile) and cyclohexane were tested by varying the composition. Figure $3(\mathrm{~b})$ shows a typical result, in which $\bar{x}_{10}$ represents the initial volumetric concentration of cyclohexane and $m$ is the initial mass of a drop. It is

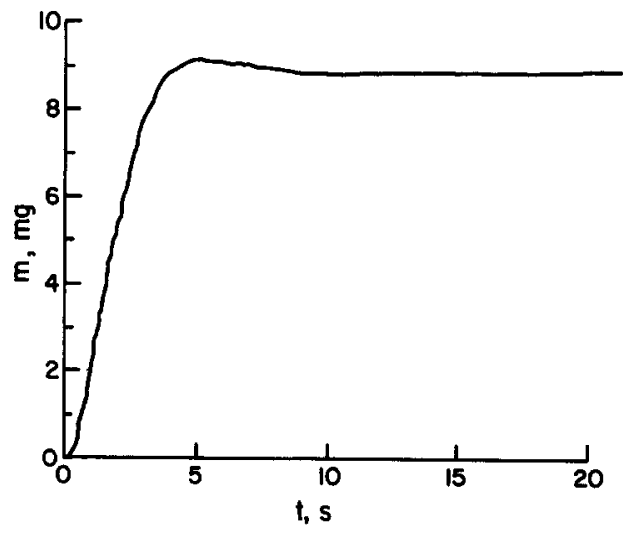

FIG. 7. Transient response of auto balance to loading of a water drop. 
observed that in a certain range of small concentrations of binary mixtures with cyclohexane (less volatile component), shorter drop lifetimes occur than with pure acetone. In other words, the evaporation rate of acetone drops is enhanced in the presence of a small concentration of cyclohexane, for example the drops with $\bar{x}_{1}=0.5$ and 0.7 , evaporate faster than the pure acctonc drop during the initial and intermediate stages of the evaporation process.

The solid circles in Fig. 5 depict the drop lifetime $t^{*}$ vs the initial acetone composition $\bar{x}_{10}$. In Fig. 5(a) for acetone-cyclohexane mixtures, the minimal lifetime occurs near the composition of $70 \%$ acetone. In the case of acetone-chloroform mixtures in Fig. 5(b), the maximum drop lifetime occurs at the acetone concentration of about $50 \%$, when $\bar{x}_{10}$ exceeds $50 \%$, the drop lifetime reduces almost linearly with $\bar{x}_{10}$.

Theoretical prediction for the time history of the drop size for acetone-cyclohexane mixtures at $14^{\circ} \mathrm{C}$, Fig. 3(a), agrees well with the experimental results in Fig. 3(b). For the positive azeotrope in Fig. 5(a), theory agrees very well with experiments. In Fig. 5(b) for the negative azeotrope, theory and experiments are in good agreement for $\bar{x}_{10}$ up to $50 \%$ beyond which theory overpredicts the drop lifetime. The disagreement was mostly due to changes in both the ambient temperatures and humidities between the days of the experiments. It is therefore concluded that the validity of the theoretical model is borne out by experiments.

It is important to note that the theory can also be anplied to non-azeotropic binary mixtures although no result is presented here.

\section{CONCLUSIONS}

A theoretical model is developed to determine the size, history and lifetime of evaporating sessile drops of binary liquid mixtures. Results agree well with experiments. Important disclosures are given below.

(1) The maximum and minimum drop lifetimes exist at the azeotropic composition of the positive and negative azeotropes, respectively.
(2) A change in $\bar{x}_{1}$ causes a reduction in the equilibrium vapor pressure, thus suppressing the vaporization process.

(3) The parameter $Z_{\mathrm{a}}$ determines the strength of vaporization in a binary liquid drop. The larger $Z_{2}$. the higher the vaporization rate.

The limitation of the model is that the heat of drop evaporation must be supplied by the substrate with negligible contribution from gas-side heat transfer. Otherwise, unsteady heat transfer would affect drop evaporation. This is especially important in free spherical drops [10].

\section{REFERENCES}

1. W. E. Acree, Jr., Thermodynamic Properties of Nonelectrolyte Solutions, pp. 48-57. Academic Press, New York (1984).

2. S. J. D. Van Stralen and R. Cole, Boiling Phenomena, Vol, 1, Chap. 2. Hemisphere, Washington, DC (1979).

3. Wen-Jei Yang, Nucleate-boiling type evaporation of binary-liquid drops on heated surfaces, Lett. Heat Mass Transfer 3, 456-474 (1976).

4. N. Zhang, Y. Xu and Wen-Jei Yang, Thermal stability in binary droplet evaporation on a flat plate by real-time holographic interferometry. Heat Transfer 1986, San Francisco, Vol. 2, pp. 525-530 (1986).

5. N. Zhang and Wen-Jei Yang, Evaporation and explosion of liquid drops on a heated surface, Exp. Fluids 1, 101-111 (1983).

6. M. G. Velarde and J. L. Castillo, Transport and reactive phenomena leading to interfacial instability. In Convective Transport and Instability Phenomena (Edited by J. Zierep and H. Oertel, Jr.), pp. 235-246. Braun, Karlsruhe (1982).

7. J. M. Prausnitz, R. N. Lichtenthaler and E. G. de Azevodo, Molecular Thermodynamics of Fluid-phase Equilibria, 2nd Edn. Prentice-Hall, Englewood Cliffs, New Jersey (1986).

8. J. M. Prausnitz, T. F. Anderson, E. A. Grens, C. A. Eckert, R. Hsieh and J. P. O'Connell, Computer Calculation for Multicomponent Vapor-Liquid and LiquidLiquid Equilibria. Prentice Hall, Englewood Cliffs, New Jersey (1980).

9. K. H. Guo, T. Uemera and Wen-Jei Yang, A reflectioninterference method to determine droplet profiles, Appl. Optics 24, 2655-2659 (1985).

10. S. Prakash and W. A. Sirignano, Liquid fuel droplet vaporization with unsteady heat transfer in the circulating liquid phase, Int. J. Heat Mass I'ransfer 23, 253-268 (1980).

\section{THEORIE ET EXPERIENCES SUR DES GOUTTES SESSILES DE MELANGES BINAIRES LIQUIDES EN EVAPORATION}

\begin{abstract}
Résumé - On étudie théoriquement et expérimentalement l'histoire et la durée de vie de gouttes sessiles de mélanges binaires liquides qui s'évaporent. Les durées de vie minimales et maximales (respectivement aux taux de vaporisation respectivement les plus forts et les plus faibles) sont atteintes pour les compositions azéotropiques, respectivement les azéotropes positifs et négatifs. Les mécanismes qui conduisent à une durée de vie extrême sont dus aux changements de composition du composant le plus voltaile pendant le mécanisme de vaporisation. Ce changement de composition tend à supprimer la vaporisation. Un nouveau paramètre sans dimension est trouvé pour déterminer l'intensité de vaporisation d'une goutte liquide binaire. Les prédictions théoriques de l'évolution de la taille de la goutte et de la durée de vie s'accorde avec les résultats expérimentaux.
\end{abstract}




\title{
THEORIE UND EXPERIMENTE ZUR VERDAMPFUNG VON HAFTENDEN TROPFEN BINÄRER FLÜSSIGKEITSGEMISCHE
}

Zusammenfassung-Grobe, zeithche Entwicklung und Lebensdauer haftender verdampiender Tropfen binäret Flüssigkeitsgemische werden theoretisch und experimentell untersucht. Die minimale und die maximale Lebensdauer der Tropfen (gleichbedeutend mit maximaler bzw. minimaler Verdampfungsrate) tritt bei den azeotropen Zusammensetzungen der positiven bzw. negativen Azeotrope auf. Die Mechanismen, die zu einer extremen Lebensdauer der Tropfen führen, beruhen auf der Konzentrationsänderung der leichter füchtigen Komponente während des Verdampfungsvorgangs. Ein neuer dimensionsloser Parameter zur Bestimmung der Verdampfungsintensität eines binären Flüssigkeitstropfens wird ermittelt. Theoretische Berechnungen der GröBenentwickhung und der Lebensdauer der Tropfen stimmen befriedigend mit experimentellen Ergebnissen tiberein.

\section{ТЕОРИЯ И ЭКСПЕРКМЕНТЫ ПО КСПАРЕНИЮ НЕПОДВИЖНЫХ КАПЕЛЬ БИНАРНЫХ ЖИДКИХ СМЕСЕЙ}

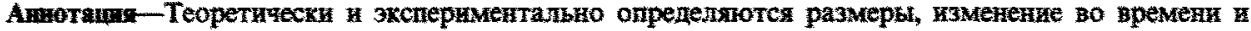

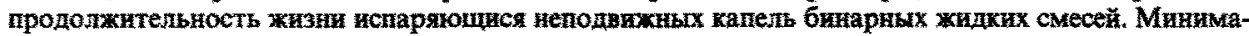
льное и максимальное снижения времени жизни (экиивалентиые соответственно максимальной и минимальной скорости испарения) происходят в азеотропных смесях положителынх и отрицательных компонентов соответственно. Механизмы, обуславливаюшие экстремальное снижение времени жизин, вызваны измекениями содержакоя наиболее летучето компонента в процессе испарения. Изменение состава приводит $\mathbf{x}$ подавлению испарения. Предложен новый безразмерньй параметр дия определения интенсивности испарения хапли бинарной жидкости. Теоретические расчеты удовлетворительно согдасукотся с зкспериментальным даниыми.
\end{abstract}

